\title{
ASMITAS - a novel application for digitalizing the SASMIT Sediment Color Tool to identify arsenic safe aquifers for drinking water supplies
}

\author{
S. Sharma ${ }^{1}$, P. Bhattacharya ${ }^{2}$, D. Kumar ${ }^{1}$, P. Perugupalli ${ }^{3}$, M. von Brömssen ${ }^{4}$, \\ M.T. Islam ${ }^{2} \&$ M. Jakariya ${ }^{5}$ \\ ${ }^{1}$ Exceldot AB, Bromma, Sweden \\ ${ }^{2}$ KTH-International Groundwater Arsenic Research Group, Department of Sustainable Development, \\ Environmental Sciences and Engineering, KTH Royal Institute of Technology, Stockholm, Sweden \\ ${ }^{3}$ Spectralinslights Pvt Ltd., Bangalore, India \\ ${ }^{4}$ Ramböll Sweden AB, Stockholm, Sweden \\ ${ }^{5}$ Department of Environmental Science and Management, North South University, Dhaka, Bangladesh
}

\begin{abstract}
Arsenic (As) contamination in groundwater is an environmental health hazard in several part of the world and a large number of population has affected due to its toxic nature. In Bangladesh, a comprehensive research was accomplished which established a very strong correlation between the aquifer sediments and As concentration in the groundwater. The local drillers practice this knowledge over a time. Based on an action research conducted by the SASMIT project team from KTH Royal Institute of Technology, Sweden in collaboration with the local drillers in Bangladesh and a novel handheld sediment color tool was produced to facilitate the local drillers to target safe aquifers for safe tube-well installation. This study was made to advance this tool to be developed as a fully artificial intelligence (AI) based digital ASMITAS (Arsenic Mitigation at Source) tool based on spectral scanning of the sediment color. An HSI camera enables us to capture continuous spectral channels from a given object ranging from IR bands, through VR to UV ranges and hence scores comprehensive imaging output over traditional RGB data based color cameras, thus increase the perception of the color with more accuracy and precision. This new tool can be scalable to cover large geographical area and hence can be very useful tool for local drillers and other stakeholders for smart decision making for installation of safe tube-wells for mitigating As at source level.
\end{abstract}

\section{INTRODUCTION}

Safe drinking water is defined as a basic human right and a specific goal for sustainable development (SDG 6) (Hossain et al., 2017; Johnston, 2016) that serves as a vital component to protect public health. The safe water access is severely impaired due to the widespread occurrence of natural arsenic (As) in groundwater in Bangladesh. Since the discovery of As in the country in 1993; several million population are still exposed to As at levels above the WHO guideline $\left(10 \mu \mathrm{g} \mathrm{L}^{-1}\right)$ and the Bangladesh drinking water standard (BDWS; $50 \mu \mathrm{g} \mathrm{L}^{-1}$ ). Keeping in view the magnitude of the human health impacts and the outcomes of the mitigation programs, the main challenge is to develop a sustainable mitigation strategy to scale up safe water access (Ahmad et al., 2017; Hossain et al., 2017). Tube-wells are most widely accepted drinking water option (Jakariya et al., 2007a, 2007b; Hossain et al., 2015), and 90\% of these tubewells are installed by local tube-well drillers, which emphasizes the important role of the tube-well drillers.

The mechanism behind the naturally occurring excess As concentrations in groundwater in the Bengal delta is the reducing condition in some sediment sections where Fe-oxyhydroxides are reduced releasing As to the groundwater (Bhattacharya et al., 1997; Ahmed et al., 2004). This implies that there is a covariation of As and ferrous iron in the groundwater. The local drillers have learnt to search for low iron groundwater and this coincides with low As (Jonsson and Lundell, 2004). The low iron and As groundwater occurs in oxidized sediments which can be characterized by the red color of the sediment (Hossain et al., 2014; von Brömssen et al., 2007) generally occurring at depths within $100 \mathrm{~m}$, accessible for the local drillers through hand percussion drilling. Since the cost of drilling with hand-percussion technology to a depth of $100 \mathrm{~m}$ is affordable for most households, it is important to enhance the capacity of the local drillers to perceive and classify sediments and identify safe aquifers. Identifying the local drillers as the main driver for the provision of safe drinking water, a novel handheld Sediment Color Tool (SCT) was developed based on the correlation of the sediment color with the As concentration in groundwater. This study advances the SCT using artificial intelligence (AI)-based digital ASMITAS (Arsenic Mitigation at Source) tool based on spectral scanning of the sediment color. Using a HSI camera, continuous spectral channels from a given 
sediment ranging from IR bands, through VR to UV ranges is captured and hence provides comprehensive imaging output over traditional color cameras using RGB data base and have a clear advantage to increase the perception of the color with more accuracy and precision.

\section{METHODS/EXPERIMENTAL}

\subsection{Understanding the scientific logic for intervention}

Having SASMIT as a concept for practical and lowcost solution to identify the aquifer sediments with low As groundwater was a major breakthrough in understanding the groundwater science. However, one of the major challenges of the SASMIT was inability to scale for other geographic location and often failed to produce reliable data on the presence of As in new areas where sediments are inadequately characterized. Digitalization of the SASMIT tool would therefore prove to be an important step to overcome some of the potential issues related to upscaling of the use of the color pallet matching tool in unexplored areas. Some of these technical challenges in SASMIT color tool are as follow:

a) The handheld tool developed in SASMIT project was based on the eye-ball matching of sediments colors and manually matching to the nearest Munsell colors, which were often challenging to define the exact reference color;

b) The correlation between the sediments colors and the As concentration in groundwater varies from place to place due to the intrinsic characteristics of the sediment layers;

c) The eye ball matching has a considerable scope for errors due to its perception under varying ambient light conditions, presence of moisture in sediments and human error in recognizing the sediment colors; and

d) The handheld sediment color tool can house the dry sediments that will have different color appearance as compared to wet color.

\subsection{Spectral imaging of the sediments}

Since over three decades, scientist and researchers are using Image Spectrometry (IS) technique to monitor environment resources, natural disasters, climate change and other natural media. The remote sensing satellite are equipped with high-resolution spectral camera to monitor earth round the clock. The new CMOS based sensor (Strle et al., 2015; Wong, 1997) has helped to design compact HSI camera and hence its affordability has resulted in its wider adoptability in several applications. The HSI camera captures several hundred of continuous spectral channels from a given object, which ranges from IR bands, through VR to UV ranges and hence scores comprehensive imaging output over traditional RGB data based color cameras. The spectrum obtained from an HSI camera has a profile

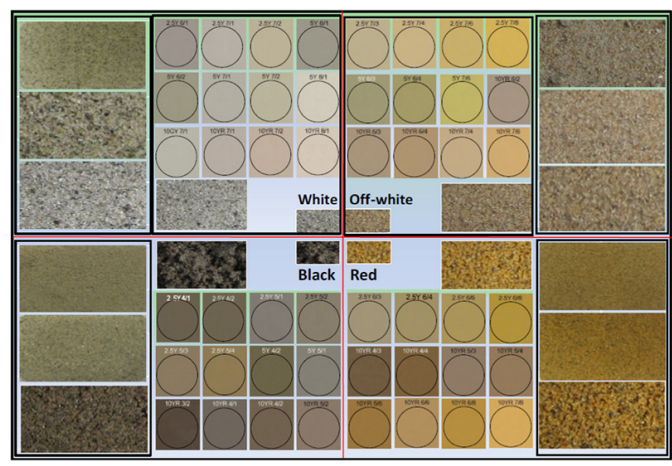

Figure 1. Color variations observed in aquifer sediment during the development of the Sediment Color Tool during the SASMIT project based on matching with Munsell color codes (Hossain et al., 2014; SASMIT, 2014).

of reflection absorption ranging from 0 to 1 for a given object with respect to various spectral band.

The spectral profiles using HSI camera could be compared with the traditional RGB sediment color and respective Munsell colors and hence can be calibrated with high level of precision.

ASMITAS constitutes two major steps, which include: i) digitalizing the reference sediments baselined with absolute As concentration in water with respect to the depth information of the tube-well based on the SASMIT study (Hossain et al., 2014; SASMIT, 2014); and ii) analysing the new samples with the reference library built on basis of the baseline sediments colors.

\subsection{ASMITAS Deep Learning Tool}

ASMITAS consists of an advanced analytic tool available both in cloud based and node-based system. The node based analytic tool provide As profiling in time span of minutes. The reference tool is being enhanced by the reference sediments images and state of the art techniques are being used to capture image of new samples and a normalized image data that is compared with the reference library. Predictive analysis tools accomplish the regression and predict the aquifers with safe levels of As in groundwater at the given depth. This can be further refined on the basis of real time analysis of the water samples and through incorporation new hyperspectral image data of the sediment color from larger geographical areas with diverse color specificities.

\section{RESULTS AND DISCUSSION}

\subsection{Core scientific logic for intervention}

ASMITAS overcomes the above challenges by means of digitalizing the sediments colors (Fig. 1) and comparing with a base reference library with very advanced algorithm based on Artificial Intelligence to estimate the color of the sediments followed by determination of As concentration on real time basis. 

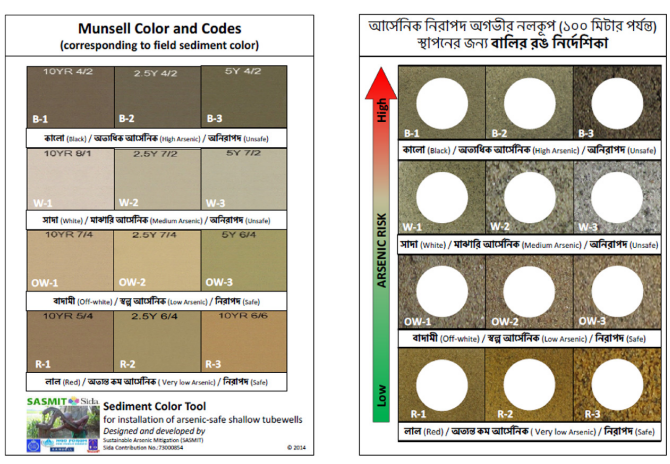

Figure 2. The SASMIT Sediment Color Tool showing the matching Munsell color codes and the risk of As in groundwater abstracted from the sediments (Hossain et al., 2014; SASMIT, 2014).

A distinct relationship of sediment color and corresponding As concentrations in well water. has been documented by the SASMIT research (Hossain et al., 2014, SASMIT, 2014; von Brömssen et al., 2007). Arsenic concentration in more than $>90 \%$ of the shallow wells installed in black sands is high with an average of $239 \mu \mathrm{g} \mathrm{L}^{-1}$ and therefore the local drillers have evolved the practice of shallow tube-well installation in red sediments where groundwater As levels are below the WHO drinking water guideline $\left(10 \mu \mathrm{g} \mathrm{L}^{-1}\right)$. Arsenic levels are also low in off-white sediments, however targeting off-white sands is limited due to uncertainties of proper identification of color, and dependent light is a an important factor must be avoided. Based on these findings a simple color based tool for targeting shallow aquifers for the installation of arsenic safe community tube-wells was developed for the local drillers (Fig. 2). The low As wells installed in red colored sediments comply with the drinking water standards for As, although concentrations of $\mathrm{Mn}$ in many of these wells are above national drinking water standards, As warrants highest attention due to its acute health effects.

\subsection{Spectral imaging of the sediments}

The spectral profile of Munsell colors were determined and compared to the sediments samples spectra profile for $0-350$ intermediate bands of spectrum. The original samples were used in the study were snapshot by Hyper Spectral Saber Camera provided by Spectral Insight, Bangalore for extending the SASMIT study. Spectral data for all the samples and Munsell colors were obtained to develop a reference library. This library can be used for analyzing the blind samples and the analytic tool can determine the As level.

The spectrum obtained from an HSI camera (Fig. 3) has a profile of reflectance based on the degree of absorption ranging from 0 to 1 for a given sediment with respect to various spectral bands related to the specific attributes of each sediment. The degree of absorption 0 represents dark sediment where all light is

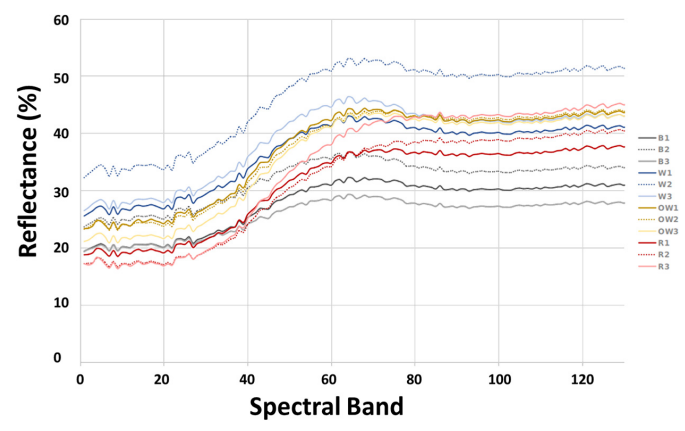

Figure 3. Spectral profiles of the reference aquifer sediments representing the four sediment color classes used for developing the Sediment Color Tool during the SASMIT project.

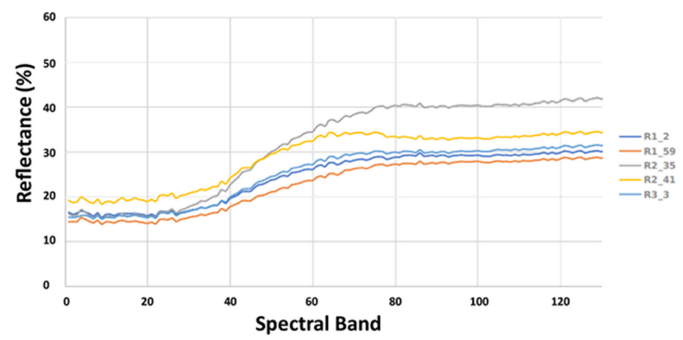

Figure 4. The spectral profiles of the blind aquifer sediments representing the five distinctive samples.
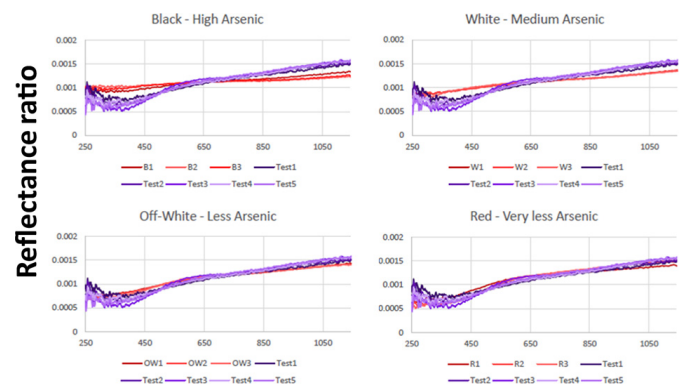

Spectral Bands

Figure 5. Comparison of the spectral profiles with the sediments color determined with respective to the Munsell colors.

absorbed and 1 represent complete white where $100 \%$ light is reflected.

In order to establish the hypothesis and its validation, spectral scans for a set of blind samples were taken by the HSI camera and the spectral profiles are presented in Figure 4.

These blind samples were further subjected to regression analysis using a statistical analysis tool. Figure 5 shows the comparison of the spectral profiles with the sediments color determined with respective to the Munsell color spectral data. Finally, all the blind samples were tested with the reference library built with digitalized aquifer sediments.

The tool suggests a very strong correlation between the blind samples with OW1, R1, R2 and R3 sets of 
Table 1. Regression analysis $\left(\mathrm{R}^{2}\right.$ error) of blind samples and reference sediments.

\begin{tabular}{llllll}
\hline Sediments & R1_2 & R1_59 & R2_35 & R2_41 & R3_3 \\
\hline B1 & 0.56 & 0.75 & 1.04 & 0.79 & 0.98 \\
B2 & 0.86 & 1.07 & 1.35 & 1.11 & 1.3 \\
B3 & 0.77 & 0.97 & 1.25 & 1.01 & 1.2 \\
W1 & 0.53 & 0.68 & 0.95 & 0.71 & 0.88 \\
W2 & 0.51 & 0.69 & 0.97 & 0.72 & 0.9 \\
W3 & 0.55 & 0.7 & 0.96 & 0.74 & 0.9 \\
OW1 & 0.35 & 0.41 & 0.64 & 0.42 & 0.57 \\
OW2 & 0.37 & 0.41 & 0.63 & 0.42 & 0.57 \\
OW3 & 0.42 & 0.38 & 0.55 & 0.41 & 0.49 \\
R1 & 0.48 & 0.4 & 0.52 & 0.43 & 0.47 \\
R2 & 0.61 & 0.36 & 0.23 & 0.36 & 0.205 \\
R3 & 0.66 & 0.42 & 0.27 & 0.4 & 0.205 \\
\hline
\end{tabular}

sediments (Table 1). The tool is also capable of offset the white correction, wet and dry sample reflectance difference and profiling of As flow in targeted area and hence offers an interesting opportunity for scaling this tool to different location.

\section{CONCLUSION AND FUTURE OUTLOOK}

The outcomes of the present study indicate that ASMITAS has the potential to overcome the challenges by means of digitalizing the sediments colors and comparing with a base reference library with very advanced algorithm based on Artificial Intelligence to estimate the color of the sediments followed by determination of As concentration on real time basis.

The ASMITAS tool can be used by the local drillers to identify the color of the sediments in a more accurate manner for targeting the safe aquifers for installation of safe drinking water wells. The tool can also be upgraded with the input of the concentration of extractable As in the sediments for characterization of the toxicity in different sediments.

\section{ACKNOWLEDGEMENTS}

The authors thank Sida-SASMIT (Contribution number 73000854) and the Sida-UNICEF project Systems strengthening and scaling up Drinking Water Safety in Bangladesh (Contribution number 52170040) for the baseline study in the process of upgrading the visual Sediment Color tool into a digitalized sediment color tool. We also thank Spectral Insights, Bangalore India for providing the Hyper Spectral Camera and the interpretative support during the realization of this study.

\section{REFERENCES}

Ahmad, A., Richards, L.A. \& Bhattacharya, P. 2017. Arsenic remediation of drinking water: an overview. In: P. Bhattacharya, D.A. Polya \& D. Jovanovic (eds.) Best Practice Guide on the Control of Arsenic in Drinking
Water. Metals and Related Substances in Drinking Water Series, IWA Publishing, UK, pp. 79-98.

Ahmed, K.M., Bhattacharya, P., Hasan, M.A., Akhter, S.H., Alam, S.M.M., Bhuyian, M.A.H., Imam, M.B., Khan, A.A. \& Sracek, O. 2004. Arsenic contamination in groundwater of alluvial aquifers in Bangladesh: an overview. Appl. Geochem. 19(2): 181-200.

Bhattacharya, P., Chatterjee, D. \& Jacks, G. 1997. Occurrence of arsenic contaminated groundwater in alluvial aquifers from Delta Plains, Eastern India: options for safe drinking water supply. Int. J. Wat. Res. Manag. 13(1): 79-92.

Hossain, M., Bhattacharya, P., Frape, S.K., Jacks, G., Islam, M.M., Rahman, M.M., Hasan, M.A. \& Ahmed, K.M. 2014. Sediment color tool for targeting arsenic-safe aquifers for the installation of shallow drinking water tubewells. Sci. Total Environ. 493: 615-625.

Hossain, M., Rahman, S.N., Bhattacharya, P., Jacks, G., Saha, R. \& Rahman, M. 2015. Sustainability of arsenic mitigation interventions - an evaluation of different alternative safe drinking water options provided in Matlab, an arsenic hot spot in Bangladesh. Front. Env. Sci. 3(30): 1-15.

Hossain, M., Bhattacharya, P., Jacks, G., von Brömssen, M., Ahmed, K.M., Hasan, M.A. \& Frape, S.K. 2017 Sustainable arsenic mitigation - from field trials to implementation for control of arsenic in drinking water supplies in Bangladesh. In: P. Bhattacharya, D.A. Polya \& D. Jovanovic (eds) Best Practice Guide on the Control of Arsenic in Drinking Water. Metals and Related Substances in Drinking Water Series, IWA Publishing, UK, pp. 99-116.

Jakariya, M., Vahter, M., Rahman, M., Wahed, M.A., Hore, S.K., Bhattacharya, P., Jacks, G., Persson, L.-A. 2007a. Screening of arsenic in tubewell water with field test kits: evaluation of the method from public health perspective. Sci. Total Environ. 379(2-3): 167-175.

Jakariya, M., von Brömssen, M., Jacks, G., Chowdhury, A.M.R., Ahmed, K.M. \& Bhattacharya, P. 2007 b. Searching for sustainable arsenic mitigation strategy in Bangladesh: experience from two upazilas. Int. J. Environ. Pollut. 31(3-4): 415-430.

Johnston, R.B. 2016. Arsenic and the 2030 Agenda for Sustainable Development. In: P. Bhattacharya, M. Vahter, J. Jarsjö, J. Kumpiene, A. Ahmad, C. Sparrenbom, G. Jacks, M.E. Donselaar, J. Bundschuh, \& R. Naidu (eds) Arsenic Research and Global Sustainability As 2016. CRC Press, Boca Raton, FL, pp. 12-14.

Jonsson, L. \& Lundell, L. 2004. Targeting safe aquifers in regions with arsenic-rich groundwater in Bangladesh. Case study in Matlab Upazila. Minor Field Studies No 277. Swedish University of Agricultural Sciences, SLU External Relations, Uppsala. ISSN 1402-3237.

Strle, D., Nahtigal, U., Batistell, G., Zhang, V., Ofner, E., Fant, A. \& Sturm, J. 2015. Integrated high resolution digital color light sensor in $130 \mathrm{~nm}$ CMOS technology. Sensors 15(7): 17786-17807

von Brömssen, M., Jakariya, Md., Bhattacharya, P., Ahmed, K. M., Hasan, M.A., Sracek, O., Jonsson, L., Lundell, L. \& Jacks, G. 2007. Targeting low-arsenic aquifers in groundwater of Matlab Upazila, Southeastern Bangladesh. Sci. Total Environ. 379(2-3): 121-132.

Wong, H.S. 1997. CMOS image sensors - recent advances and device scaling considerations, IEEE IEDM Technical Digest, pp. 8.5.1-8.5.4. 